\title{
Effects of Economic Uncertainty on Mental Health in the COVID-19 Pandemic Context: Social Identity Disturbance, Job Uncertainty and Psychological Well-Being Model
}

\author{
${ }^{1}$ Danijela Godinic, 2 Bojan Obrenovic, ${ }^{3}$ Akmal Khudaykulov \\ ${ }^{1}$ FFZG, Faculty of Humanities and Social Sciences, Zagreb, Croatia \\ 2 School of Management, Jiangsu University, Zhenjiang, China \\ ${ }^{3}$ School of Management, Huazhong University of Science and Technology, Wuhan,
}

China

\begin{abstract}
Psychological well-being is a major global concern receiving more scholarly attention following the 2008 Great Recession, and it becomes even more relevant in the context of COVID19 outbreak. In this study, we investigated the impact of economic uncertainty resulting from natural disasters, epidemics, and financial crisis on individuals' mental health. As unemployment rate exponentially increases, individuals are faced with health and economic concerns. Not all society members are affected to the same extent, and marginalized groups, such as those suffering from chronic mental illnesses or low-income families cannot afford the downsizing, mass lay-offs and lack of access to public health services. Psychiatric profession is familiarized with the phenomenon of intolerance of uncertainty (IU), and we examine how this concept is associated with job uncertainty and social identity disturbance. Several studies have formally investigated the effects of IU, but to our knowledge, this is the first research integrating the psychological well-being, job uncertainty and identity disturbance caused by economic breakdown. Literature points to many reported cases of PTSD, anxiety, depression and suicidal tendencies following major social disasters. Yet, we have undertaken to analyze the subjective experiences underlying the self-harming behaviors in an attempt to fill the methodological gap by drawing insights from prominent psychological, sociological and economic theories. We find economic uncertainty to have a positive relation to job uncertainty and identity disturbance, and a negative relationship with psychological well-being. Psychological well-being depends on coherency between both abstract subjective and concrete objective identity, and when these perceptions are inconsistent, cognitive dissonance arises resulting in identity disturbance. We argue that stability is not associated with monetary advantage only, but also with a wide range of other benefits that are crucial for individuals' growth, satisfaction and sense of identity. Therefore, we propose the implementation of social support and public welfare policies to mitigate health risks during the turbulent socio-economic changes.
\end{abstract}

Keywords: COVID-19 psychology, COVID-19 economy, Economic uncertainty, Psychological well-being, Job uncertainty, Identity disturbance, Mental health

\section{Introduction}

The uprising COVID-19 epidemiological and economic crisis prompted serious challenges with regards to socio-economic determinants of mental health. Economic uncertainty is the highrisk period for the overall mental well-being of individuals, their spouses and relatives (Holland, 2016; Dohrenwend, 2000). Lesson learned from the past, such as the 2008 financial crisis provide insight into possible problematic points and knowledge about mitigating potential risks. First of all, not all members of society are equally affected by the crisis. What we do know is 
that declines in economic activities may cause cognitive and affective disturbances as a result of the combination of many devastating factors, such as unemployment, downsizing of medical and social services, and cut in public spending (Meltzer et al., 2010). All of these combined with job uncertainty, and uncertainty of future, in general, cause serious mental damages, and result in the occurrence of intolerence of uncertainty induced depressive-anxiety disorders (Wright et al., 2016). Particular focus should be on the already marginalized groups, stigmatized or diagnosed individuals. The already existent diseases may become more intensive and chronic during the crisis (Cai et al., 2018). The reason for this is that many countries are downsizing their spending on medical health insurance services, especially in the public sector, and these individuals rarely have key resources available and access to private practice psychotherapy.

Marginalized groups are expected to be severely affected by insecurity, fear of losing a job and reduced income, falling in debts, unavailability of essential goods, social isolation, and unhygienic living conditions. The crisis is already prompting even broader social exclusion of vulnerable groups by stigmatizing them. This may include mentally impaired, low-income families, unemployed individuals, migrants and undocumented workers. Extreme impoverishment results in cognitive, affective and physical deficit. People struggling with excessive financial difficulties are prone to mental health issues such as depression, substance abuse, especially alcohol abuse, and suicidal tendency (Yang et al., 2017b). The more debt they struggle with, the higher the likelihood of mental disorders (Jenkins et al.,2016). According to an empirical study of Stuckler et al. (2009), after the rise of unemployment, there was a $28 \%$ increase in suicide rates in the EU. Leaders are required to intervene with strategically devised social protection programmes for risky hypersensitive population.

Many countries around the globe have established restrictions and policy measures with regards to social distancing, remote working, and self-isolation. The economic implications have been severe. COVID-19 pandemic is a global threat to populations' financial status caused by the breakdown of majority supply chains and daily business activities. Acceptance of strict regulations restricts social interaction, which is one of the main pillars of psychological wellbeing and resilient identity. Furthermore, we are concerned with psychological and psychiatric effects of economic uncertainty. The very unpredictability and lay-offs lead to severe mental disorders, and subsequent financial debts and inaccessibility to medical treatment cause a generally healthy population to experience the pathological state of identity disturbances.

Other mood and affective disorders may arise, such as depression, anxiety, PTSD, substance abuse, and suicidal ideation. We find that in the time of need, reaching out to one's usual social support network is disrupted, and individuals fail to meet their innate needs for affiliation and acceptance. Rapid changes on the labour market spread the panic of uncertainty, and job loss and inability to associate with relevant others cause not only stress-induced mental conditions harmful to psychological well-being but also identity disturbances where individuals are faced with discrepancies between their prototypical and subjectively perceived identities and newly emerging reality. Society is changing by and large, and some find it more struggling to readjust.

We contribute to the existing body of knowledge by adopting previously established and empirically confirmed mental health implications. We integrate these constructs in a new conceptual framework and apply it in the context of COVID-19 outbreak for testing the psychological and psychiatric effect of uncertainty. The main contribution of the study is in that it identifies which specific stressors threaten societies' health and which operations should the government, as well as ministries and public health officials undertake to mitigate risks posed by COVID-19. Establishing and validating the assumptions of the new framework for examining the impact of social identity disturbance on mental health is being sought. Individuals behave differently during the pandemics and need to adopt healthy coping strategies, as well as cognitive and behavioural patterns. We have conceptualized an innovative approach by 
determining specific factors undermining the psychological well-being that are direct consequences of COVID-19.

\section{Theory and Research Model Development}

In research model development, we have built on the theoretical grounds of Conservation of Resources Theory, Self-Determination Theory, Social Identity theory and Identity -Unertainty Theory. First, under the assumptions of Conservation of Resources Theory, health is deemed a valuable resource contributing to overall psychological well-being. Furthermore, full-time employment, monetary and non-monetary work benefits, structure, social support and financial stability are considered to be critical resources contributing to individuals' growth, satisfaction and sense of identity (Yousaf et al., 2019; Newman et al., 2018; Hobfol et al., 1990). Economic uncertainty, followed by a mass lay-offs, cut-downs, inflation and debts causes emotional exhaustion and psychological strain (Lim et al., 2018; Meltzer et al., 2010). Individuals are deprived of essential resources, and the blow is even harder for marginalized groups, such as population suffering from mental disorders, poor and low-income families, immigrants and undocumented workers (Heath et al., 2012, Hobfol et al., 2011). Social isolation and remote working policy have already deprived a number of people of key resources such as self-esteem, positive attitude, self-accomplishment, self-efficacy and social support which would usually be utilized as a source for establishing a coping mechanism to reduce stressors (Jesus et al., 2016).

Self-determination Theory posits that people engage in activities they find motivating, meaningful and valuable (Ryan and Deci, 2000). Work projects are a source of psychological, social and relational satisfaction. Job promotes well-being by allowing people to meet their needs for survival, affiliation, and belonging. Watching themselves accomplish diverse tasks, acquiring new skills and knowledge and sharing emotional and cognitive support with co-workers contributes to one's sense of sel-worth and boosts confidence (Obrenović et al., 2015). One of the fundamental human needs is the desire to associate, stay connected, to care and be cared for (Flum, 2015). When met, it allows for efficient functioning and personal growth. Conversely, losig employment and falling into financial debts lead to isolation, depression, identity disturbance, cognitive dissonance and consequently, mental illness (Blustein et al., 2019).

Social identity theory posits individuals' sense of self is based on the group membership and roles one assumes. Groups provide people with social identity, and they are especially relevant in stressful situations, since the need for social support is amplified when one cannot control the outcomes while dealing with uncertainty. This especially holds for people with dependent personality, since they will suffer more due to their need for approval and company. Social identification manifests as internalizing the group identity and forming an attitude towards ingroup members, as well as social comparison with other groups. Therefore, if one classifies as a healthy, extroverted individual, worker of specific organization, any circumstance that threatens his identification or membership will likewise threaten his personal identity, causing cognitive dissonance and identity disturbance. Since identity refers to self-definition as being a part of a wider community and is therefore dynamically associated with societal conditions, fear of poverty, social exclusion and marginalization may seriously damage self-esteem (Elliot, 2015). Economic uncertainty brings about an atmosphere of contingency, unpredictability, and discontinuity, making it challenging to attain and maintain a strong sense of identity (Johansson, 2006). Uncertain times often have a significant impact on people's context and situation dependent identities, and certain economic factors may modify one's social and economic status. Identity is at the same time personally and social constructed (Vignoles et al., 2011). Diverse socially constructed semi-identities help people navigate different situations (Wetherell and Mohanty, 2010). Identity disturbance stems from psychoanalytic construct of identity diffusion, a pathological state whereby one experiences disintegration of inner continuity and problems with occupational, social, and intimate relations. Kernberg (1985) refers to it as "the lack of an 
integrated self-concept and an integrated and stable concept of total objects in relationship with the self" (p. 39)

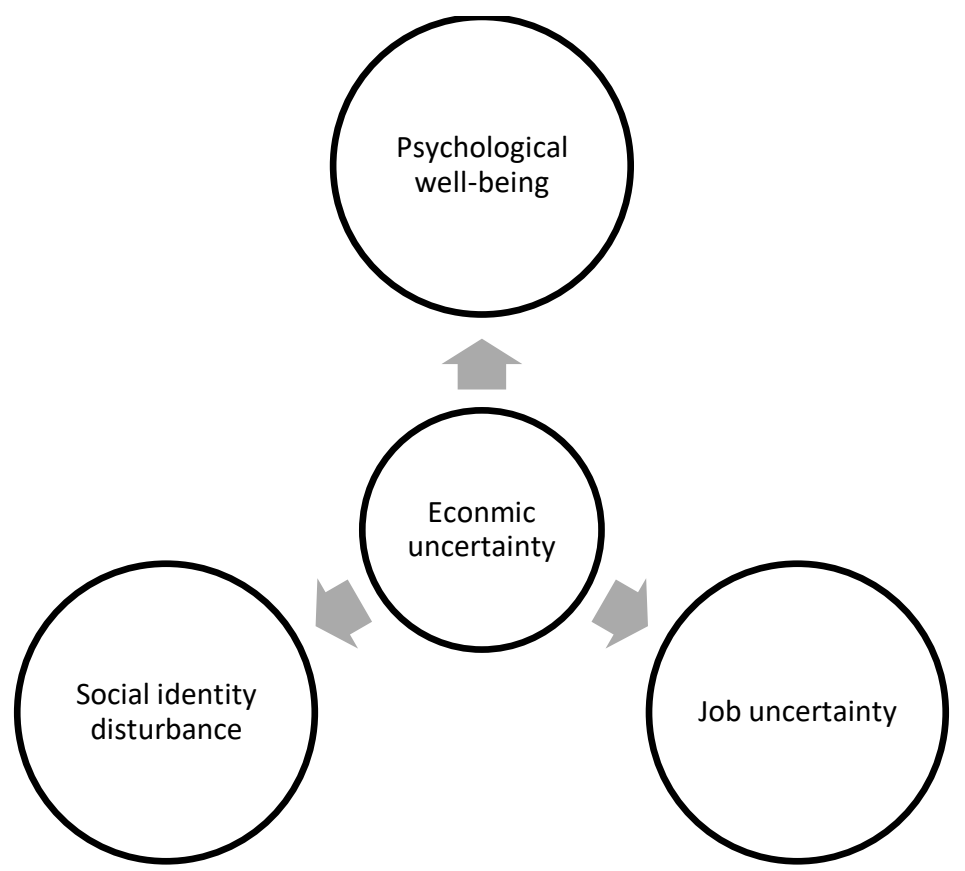

Figure 1: Research model

\subsection{Psychological Well-Being}

COVID-19 pandemic created a pervasive atmosphere of general uncertainty concerning the overall state of the economy, finances, social relations, and health. Social distancing and isolation cause severe damage to psyche and well-being, followed by a drastic increase in the number of reported cases of mental disorders and suicidal ideation (Kawohl and Nordt, 2020). Breakdown in social interaction and losing control are not only drivers of mental deterioration but also economic uncertainty (Reneflot and Evensen, 2014). As the number of unemployed individuals exceeds 190 million, there are raising concerns about future employment, financial income, mortgages, and the rate of post-crisis economic recovery (Gangopadhyaya and Garrett, 2020). All of these concerns have put strains on individuals' well-being, as well as the well-being of entire societies (Pompili et al., 2014).

Uncertainty is characterized as the presence of ambiguous, complex, and unpredictable conditions and a lack of information availability and consistency, where people doubt public, general, and their own knowledge (Brashers, 2001). Building on Conservation of Resources Theory, every uncertainty has a detrimental effect on mental health, causing psychological distress and emotional exhaustion due to deprivation of resources that are invested in regulating the mood and maintaining stability. Psychological well-being relates to positive emotional and mental states, such as happiness and satisfaction. The construct refers to the extent to which individuals experience positive emotions in life with regards to meaningful and affectionate relationships with others, personal growth, purpose in life and autonomy free of social pressures. Psychological well-being is influenced by previous experience and underlying personality, and while it is relatively stable during one's lifetime, stressful events and traumatic experiences may predispose individuals to mood and anxiety disorders (Gladstone et al., 2004). Such are the incidences of major catastrophic events of natural disasters or epidemics like COVID-19, posing great threat both to physical and mental welfare. Many studies reported the impact of financial stressors of economic crises on psychological well-being (Jesus et al., 2016; Catalano et al., 2011; Althouse et al., 2014). Economic uncertainty was associated with distress, depression, 
PTSD (Leon, 2004; Neria et al., 2007), anxiety (Foa et al., 2006), dysfunctional impulsivity, suicidal ideation, and hypertension.

Following the disastrous effect of 2008 financial crisis, business scholars, economists, psychologists, and psychiatrists worldwide have focused on exploring the impact of unemployment on psychological health and well-being (Green, 2011; Huber et al., 2011). Several studies found that the Great Recession caused a staggering amount of suicide instances and mental illnesses (Lo and Cheng, 2014; Phillips and Nugent, 2014). For example, mental health was negatively affected by the Recession period and unemployment (Flin et al., 2013). Significant attention was dedicated to the investigation of the relationship between economic challenges and suicidal rate (Branas et al., 2015; De Vogli et al., 2013). It was also theorized that economic pressure has a detrimental effect on families. Married couples are often uncertain about spending, financial management and problems, struggling to communicate their worries and find an optimal solution even during stability. Moreover, economic uncertainty prompts imagining of different negative scenarios and damages psychological well-being (Leininger and Kalil, 2014). Dissatisfaction and perceived unmanageability stemming from crisis put a strain on a lot of marriages, resulting in increased conflict, divorce rate and propensity for partner violence (Obrenovic et al., 2020; Lucero et al., 2016). Gradual built up of collective fear, panic, depression, aggression, and agitation all induce marital arguments, as people are more prone to lashing out on a partner when they're coping with acute problems under severe stress.

In a response to COVID-19 crisis, many state-level policies were implemented to help save countries' economies, and to avoid major closings, salaries were reduced. Employees relying heavily on extrinsic rewards and incentives to boost their self-esteem, may now feel less accomplished and experience depression (Giorgi et al., 2015). Job insecurity is a stressor on its own. Work functions as a major determinant of individual well-being, and this is the exact reason why public welfare policies aiming at increasing collective psychological well-being typically include measures and interventions for the working population and prospective working population, such as career development counselling, scholarship and training. Depression and anxiety were associated with impaired psychosocial and occupational functioning (Hussain et al., 2011; Alonso et al., 2004; Druss et al., 2009). The health of the populations depends upon socioeconomic conditions, medical, education and employment policies, and it is plausible that each shift in these determinants will be reflected in societal well-being. Economic uncertainty aggravates mental illness through risk factors of unemployment, downturns, debts, and recession. It is possible to measure the decrease in the psychological well-being of individuals during COVID-19, as well as other economic uncertainty crisis by a number of available indicators, such as symptomatic self-rated test and reports, reports on substance-abuse, reports on self-harming behaviour and suicidal mortality rate reports. Economic variables to be considered are pre-crisis and post-crisis period financial state, unemployment rate, contraction in GDP. The economic breakdown caused by catastrophes is often followed by an increase in depression and anxiety disorders since it affects not only psychological and physical health but also causes disruptions in a healthy emotional and social functioning (Reichert and Tauchmann, 2011).

Therefore, we conclude the following:

\section{Hypothesis 1. Economic uncertainty has a negative impact on psychological well- being}

\subsection{Job Uncertainty}

There is a growing body of research focusing on the health repercussions of job uncertainty (Marcus, 2012; Deb et al., 2011; Browning and Hinesen, 2012). It is only logical that disasters such as COVID-19 characterized by economic uncertainty will bring about a job uncertainty, and prompt general depression, an increase in suicidal tendencies (Eliason and Storrie, 2009), and mental disorders that can be measured using General Health Questionnaire (GHQ-12). Apart 
from monetary, a job ensures many non-monetary benefits, such as actively organized time, social status, higher purpose, organizational participation, access to training, medical care, insurance and counselling, statutory entitlements, feeling of accomplishment etc. (Breman and van der Linden, 2014). The self-efficacy belief, sense of being able to follow through, develop and contribute is one of the central aspects of organizational behaviour (Parker, 2014). In line with self-determination theory, people tend to engage in activities they consider motivating and meaningful (Ryan and Deci, 2000). Working promotes well-being by enabling one to meet his relational needs (Flum, 2015), and losing job leads to isolation and depression since one becomes deprived of relational interaction which is one of the most valuable psychological resources (Blustein et al., 2019; Wanberg, 2012). Scholars often define job insecurity as "the overall concern about the future existence of the job" (Rosenblatt and Ruvio, 1996). Since the concept does not include one's entire career or prospect jobs but is restricted to a current position and employer, it relies on unique organizational, social and economic factors, which in turn influence it.

Furthermore, it is comprised of cognitive and affective elements (Huang et al., 2012a). Cognitive job insecurity relates to the perception of the probability of negative changes, while affective represents the experience of being in the state of anxiety over losing the job. In line with appraisal and COR theory, some scholars have posited a reciprocal relationship between job insecurity and employee well-being due to a viable threat to the valuable resource (Vander Elst et al., 2014b; Endler et al., 2001). Job insecurity is a stressor consuming mental and affective resources thus causing psychological strain (Staufenbiel and Konig, 2010). Furthermore, according to the Social Exchange Theory, individuals and organization form an exchange relationship, where employees expect job certainty from the employer. When this is achieved, it is called person-organization fit (Margaretha and Wicaksana, 2020). In the time of uncertainty, when this security may not be provided, they withdraw their efforts and resources. Drawing on the stress-retention model of absenteeism, employees' negative appraisal of economic uncertainty and job uncertainty will increase psychological distress and absenteeism from work (Montani et al., 2019).

Wang et al. (2015) found that for employees, fair treatment is even more critical in the time of uncertainty than during stability. When a crisis strikes, individuals who dwell on their ability, competency or future employability will perceive the crisis as more acute, alarming and destabilizing. Perceived alternatives, whether grounded in real conditions or not, are better means for dealing with uncertainty since one's perception is his subjective reality and may feel as acute as real-world objectivity (Huang et al., 2013). Yet, the actual employability is also helpful in times of economic uncertainty (Giorgi et al., 2015). Additionally, supervisor support and sharing of information may help to mitigate the risks of psychological distress. In contrast, withholding of crucial information regarding the certainty of one's future employment status reduces psychological well-being.

The most severe consequences of this macro-scale global crisis are job uncertainty, unemployment, and health risks. Inflation decreased income, increase in health-care costs and lower capacity of social services all come at the expense, and it is not necessarily financial expense. Often, a job provides a certain level of security and functions as a buffer against extreme panic, and job uncertainty annihilates this shield and exposes one to drastic fear that may result in PTSD.

Individuals are not vulnerable to job uncertainty to the same extent. For instance, immigrant or undocumented employees will not be affected by the crisis equally as permanently employed, since they will lack experience and tenure due to missing papers. Also, it would be more challenging for them to find opportunity quickly, which makes them even more fearful (Frasquilho et al., 2016). Often employees working without application and for lower wages have an entire family relying on them for continuity; therefore, they will be more alarmed by 


\section{Danijela Godinic, Bojan Obrenovic, Akmal Khudaykulov \\ Effects of Economic Uncertainty on Mental Health in the COVID-19 Pandemic Context: Social Identity \\ Disturbance, Job Uncertainty and Psychological Well-Being Model}

perceived uncertainty. Furthermore, any news about job loss or lay-offs from friends and family will increase the fear of economic uncertainty. After the 2008 economic Recession, almost half European citizens reported knowing someone who had lost the job due to crisis (European Commission Report, 2013). Psychologists and psychiatrists alike have already pointed out that anticipation of a stressful event is at times a higher source of angst than the event itself (Lazarus and Folkman, 1984). Caroli and Goddard (2016) found that job insecurity may be more stressful than the actual lay-off since knowing of unemployment helps one to focus on planning future actions, while anticipation leaves one struggling.

Therefore, we conclude the following:

\section{Hypothesis 2. Economic uncertainty has a positive impact on job uncertainty}

\subsection{Social Identity Disturbance}

Social identity theory posits that an individuals' sense of who they are is based on the group membership in the relevant social associations one inhabits. Groups provide people with a social identity, sense of belonging and satisfy the basic need for affiliation. The self is constituted of different semi-identities one attributes to his being, and for the mental stability and continuous sense of being these identities are to be verified in a social context by other people (Berger and Luckmann, 1967; Laing, 1960). Côte and Levine (2002) differentiate between personal level identity relating to behavioural person-specific patterns and group level identity following from association in certain social groups and their meanings. When a crisis arises, such as COVID-19 public welfare policy of social distancing and inherent economic uncertainty, people are experiencing identity disturbances, depression, and may even exhibit symptoms of temporary psychosis. Pandemic has even more dangerous effect on those already suffering from mental health issues, especially personality disorders. Those on the borderline and schizophrenia spectrum may under stress experience dissociative states associated with excessive selfcriticism (DSM-V). The crisis will hit the hardest people experiencing identity disturbances, but this does not mean it can't have severe consequences for healthy people as well. Identity disturbance refers to the lack of continuity in self-image, confusion about oneself, uncertainty about aspirations, values, choices and long-term goals, including career plans. Following this, it's not hard to understand why many functional people may experience instability during economic uncertainty, especially when the increase in unemployment has left people with general fear and insecurity regarding their future, and their prospective careers.

Furthermore, it is not rare that a person identifies with his social or work role, and begins to define his status and character in terms of the function they exercise. Disruption of business as usual caused reconfiguration and reorganization of work activities in many enterprises, resulting in redefining certain positions and forming new emergent teams. These emergency strategies may lead to increased role ambiguity and role conflict, causing stress and damage to individuals' psychological well-being. The more individuals have identified themselves with their roles, the less flexible they are and the more identity disturbance uncertainty will stimulate. DSM-5 Diagnostic Statistics Manual for mental disorders describes it as having an unstable self-image or sense of self, with a lack of clear aims and internal preferences. Zanderson and Parnas (2019) in examining the phenomenological nature of identity disturbance differentiate between "core" and "narrative" selfhood, and discrepancies may occur along both of these lines.

Cognitive dissonance may occur when an individual who perceives his identity in a certain way is affected by the crisis and uncertainty to that extent that his current state contradicts his-selfimage. As a consequence, damage to psychological well-being may lead to mental disorders and social dysfunction while an individual try to work through his subjective self-identity and his objective identity in a new situation. Dissonance happens when individuals are faced with information that is conflicting to their already existing beliefs, opinions and values, causing the unpleasant sense of being caught between opposite forces (Iyenegar, 2010). To eliminate the dissonance, people often engage in self-deception, and this leads to two paradoxes of what 
Lipari (2018) refers to as motivational bias. One coping strategy to eliminate the distress caused by economic uncertainty is concerned with maintaining a specific self-assessment belief, such as rendering sills one does not possess irrelevant or stressing the value of traits one has (Oxoby, 2004; Rabin 1994). This may be harmful when one is ascribing a certain status or social position to himself, and his economic and objective reality is far different.

Burke (2020) defines identity as a set of meanings one holds with regards to what it means to be who one is in a role it assumes, therefore it is an umbrella term for role identities, social identities and personal identities. Following the uncertainty-identity theory (Hogg, 2007), when people are uncertain about the self, they begin to devalue themselves. The psychoanalyst Erik Erikson (1968) described identity as experiencing the continuity and sameness of the self that stems from devoting to certain ideals, virtues and goals. Goals guide individual in pursuing objectives in order to fulfill one's need in a given environment (Hudaykulov et al., 2015). Since identity refers to self-definition as being a part of a wider community and is therefore dynamically associated with societal conditions, fear of poverty, social exclusion and marginalization may seriously damage self-esteem (Elliot, 2015). Recent sociological studies take identity instead of static, to be multidimensional, constituted of diverse context-dependent, social and relationally defined semi-identities which individual utilizes to manage and navigate through different situations (Wetherell and Mohanty, 2010). These are fluctuating, indeterminate and dependent on more comprehensive socio-economic settings. Therefore, identity is simultaneously fluid and stable and personally and socially constructed (Vignoles et al., 2011). Limited access to work (Fabian, 2013), financial resources (Thompson et al., 2017; Smith, 2015), healthcare services and poverty (Flores et al., 2017) result in psychological, social and economic damage (Blustein et al., 2019). Economic uncertainty brings about an atmosphere of contingency, unpredictability and discontinuity, making it challenging to attain and maintain a strong sense of identity (Johansson, 2006).

Therefore, we conclude the following:

\section{Hypothesis 3. Economic uncertainty has a positive relationship with social identity disturbance}

\section{Discussion}

When economic uncertainty emerges, people are less prone to prosocial behaviours due to their concern and occupation with arising financial and family situation. Crises may have enormous long-term consequences for health and liquidity of not just individuals, but entire societies, and drawing from the previous disaster lessons, a new "normal" will for some time be a state of general panic, worry, anxiety and job insecurity. COVID-19 has already caused the bankruptcy of many enterprises, lock-downs, shut-downs of businesses, employee lay-offs, lack of resources, and more is to follow in the following months. It is not absurd to imagine many will experience trauma-inducing fear of losing the job, and some will leave the pandemic with PTSD. Since work has functions directly related to individuals' psychological health and self-esteem, job insecurity inevitably has implications to one's identity, self-efficacy beliefs, confidence and social support system. The threat is thus not only financial but rather multidimensional. Losing a job often entails depression and self-isolation, and since no man is an island, withdrawal is detrimental to psychological well-being. Economic hardship is associated with mental health problems (Greenglas et al., 2014). Economic turmoil posing job uncertainty may result in distress, feeling of helplessness, suicidal ideation, paranoia, and substance abuse (Prawitz et al., 2006; Almeida and Xavier, 2013). Unemployment is found to be associated with mental health (Bijlsma et al., 2017; Jofre-Bonet et al., 2018), and job insecurity leads to severe psychological damage (Caroli and Godard, 2016; Bünnings et al., 2017), especially considering the possible consequences of losing jobs such as social stigma and loss of social support (Gathergood, 2005). 
Possessing a sense of identity and coherence regarding one's aspirations and meaning in life is crucial for social integration (Mannerström, 2019). Knowing who you are and where you see yourself in the future is essential for psychological well-being, and precisely this experience of stability, continuity and identity is bound to decrease when economic uncertainty strikes. Socioeconomic circumstances are related to a person's financial, occupational and developmental state. One achieves a sense of identity with independence, and in large independent cohabitation, good education, financial stability and permanent employment help to build identity resilience (Elder and Giele, 2009). Economic uncertainty has already resulted in many lockdowns, downsizing and employee lay-offs. Uncertainty may manifest as the negative experience of doubt and ambiguity that is induced by external conditions and situations. When people lose jobs, or when they are quarantined, they lack the necessary confirmation, psychological and social support and verification, they are used to receive in the workplace. The greater the necessity for affiliation, the greater the psychological distress during the crisis will be (Casale and Flett, 2020). Interpersonal fears of missing out and fear of not mattering may become acute and have a severe impact on identity for people now confronted with inconsistency between their innate needs and the new reality. Those who have lost their jobs due to current crisis may have difficulties in readjusting and coming to terms with the new situation that requires probabilistic reasoning (Aitken and Mavridis, 2019). They will struggle to reconcile their prior and new identity, as many of them are rapidly becoming a part of the unemployed or low-income population.

\section{Conclusion}

Mental health is the essence of public health and it is significant for many countries going through the same economic crisis, either by laying off employees or by being deprived of a vital labour force due to psychological consequences. Following the Conservation of Resources Theory, health is considered to be a resource for overall well-being, whereby healthy worker invests his cognitive capital and energy to increase organizational performance and productivity. Under the usual conditions that are characteristic for stability, positive attitude towards one's self-efficacy and accomplishment are deemed a resource that may be utilized as a coping strategy in reducing stressors. But for the ones that experienced mental health disturbances even before the crisis, it may be the case they lack these resources, thus practising absenteeism and withdrawal. Disordered people lack the flexibility that underlies identity resilience amid stress and chaos, and they find it more difficult to readjust to the emerging situation. The economic repercussions of mental problems identified as the loss in productivity were estimated to $3-4 \%$ of GDP in the European Union during the Great Recession (WHO, 2007). To achieve sustainability and efficiency as a driving force to overcome uncertainty and stimulate growth, it is critical to attend to the national mental health and devise incentives and social-welfare policies providing disabled individuals with necessary treatment and support during the crisis. Working advances mental health, therefore job certainty is one of the main pillars providing stability. When the uncertainty emerges, all sense of perceived control diminishes, and the need for selfactualization and relatedness is threatened. The mind responds to a perceived threat in diverse ways, but when such danger is prolonged, one may resort to isolation and fall into a depressive state, and even become suicidal. It can be said that permanent employment and regular income predicts good mental health, and from that, we can infer what is the case when unemployment and instability arises. Economic uncertainty and job uncertainty will lead to reduced psychological well-being. The working arrangement provides an individual with meaningful social relationships and commitment, civic participation, trust and a sense of belonging. One of the biggest threats to mental health stems not from the loss of monetary rewards, but social and relational deprivation and decrease in self-determination. A more in-depth insight into the psychological dynamics of crisis and hazards help to devise schemes, welfare policies and healthcare initiatives for individuals to facilitate coping with catastrophic events. By 
understanding these circumstances, more efficient strategies can be employed to prevent the increase of mental illnesses and lower the extremity of economic consequences.

\section{References}

- Aitken, C., \& Mavridis, D. (2019). Reasoning under uncertainty. Evidence-based mental health, 22(1), 44-48. Crossref

- Almeida, J. M. C., \& Xavier, M. (2013). Estudo epidemiológico nacional de saúde mental: $1^{\circ}$ relatório [National epidemiological study of mental health: 1st report]. Lisboa: Faculdade de Ciências Médicas, Universidade Nova de Lisboa

- Alonso J, Angermeyer MC, Lépine JP. The European Study of the Epidemiology of Mental Disorders (ESEMeD) project: an epidemiological basis for informing mental health policies in Europe. Acta Psychiatr Scand. 2004;109:5-7. doi:10.1111/j.1600-0047.2004.00325.x. Crossref

- Althouse, B., Allem, J., Childers, M., Dredze, M., \& Ayers, J. (2014). Population health concerns during the United States' great recession. American Journal of Preventive Medicine, 46, 166-170 Crossref

- Berger, P. L., Luckmann, T., \& Zifonun, D. (1967). The social construction of reality.

- Bijlsma, M.J., Tarkiainen, L., Myrskylä, M. and Martikainen, P., 2017. Unemployment and subsequent depression: A mediation analysis using the parametric G-formula. Social Science \& Medicine, 194, pp.142-150. Crossref

- Blustein, D. L., Kenny, M. E., Di Fabio, A., \& Guichard, J. (2019). Expanding the impact of the psychology of working: Engaging psychology in the struggle for decent work and human rights. Journal of Career Assessment, 27(1), 3-28. Crossref

- Branas, C.C., Kastanaki, A.E., Michalodimitrakis, M., Tzougas, J., Kranioti, E.F., Theodorakis, P.N., Carr, B.G. and Wiebe, D.J., 2015. The impact of economic austerity and prosperity events on suicide in Greece: a 30-year interrupted time-series analysis. BMJ open, 5(1), p.e005619 Crossref

- Brashers, D. (2001). Communication and uncertainty management. Journal of Communication, 51, 477- 497. Crossref

- Breman, Jan and Marcel van der Linden, 2014. "Informalizing the Economy: The Return of the Social Question at a Global Level", Development and Change, Vol. 45, pp. 920-940 Crossref

- Browning, M. \& Heinesen, E. (2012). Effect of job loss due to plant closure on mortality and hospitalization. Journal of Health Economics, 31(4), 599-616. Crossref

- Bünnings, C., Kleibrink, J. and Weßling, J., 2017. Fear of Unemployment and its Effect on the Mental Health of Spouses. Health Economics, 26(1), pp.104-117. Crossref

- Burke, P. J. (2020). Identity Dispersion: Flexibility, Uncertainty, or Inconsistency?. In Identity and Symbolic Interaction (pp. 89-117). Springer, Cham. Crossref

- Cai, R. Y., Richdale, A. L., Dissanayake, C., \& Uljarević, M. (2018). Brief report: Interrelationship between emotion regulation, intolerance of uncertainty, anxiety, and depression in youth with autism spectrum disorder. Journal of Autism and Developmental Disorders, 48(1), 316-325. Crossref

- Caroli, E. and Godard, M., 2016. Does job insecurity deteriorate health?. Health Economics, 25(2), pp.131-147. Crossref

- Casale, S., \& Flett, G. L. (2020). INTERPERSONALLY-BASED FEARS DURING THE COVID-19 PANDEMIC: REFLECTIONS ON THE FEAR OF MISSING OUT AND THE FEAR OF NOT MATTERING CONSTRUCTS. Clinical Neuropsy

- Catalano, R., Goldman-Mellor, S., Saxton, K., Margerison-Zilko, C., Subbaraman, LeWinn, K., \& Anderson, E. (2011). The health effects of economic decline. Annual Review of Public Health, 32, 431-450. doi: 10.1146/annurev-publhealth Crossref

- Côté, J. E., \& Levine, C. (2002). Identity formation, agency and culture: A social psychological synthesis. Mahwah, NJ: Lawrence Erlbaum Associates, Inc. 
- De Vogli, R., Marmot, M. and Stuckler, D., 2013. Excess suicides and attempted suicides in Italy attributable to the great recession. J Epidemiol Community Health, 67(4): 378-379. Crossref

- Deb, P., Gallo, W. T., Ayyagari, P., Fletcher, J. M., \& Sindelar, J. L. (2011). The effect of job loss on overweight and drinking. Journal of Health Economics, 30(2), 317-327 Crossref

- Dohrenwend B. P. (2000). The role of adversity and stress in psychopathology: some evidence and its implications for theory and research. J. Health Soc. Behav. 41 1-19. [PubMed] [Google Scholar] Crossref

- Druss, B.G., Hwang, I., Petukhova, M., Sampson, N.A., Wang, P.S., Kessler, R.C., 2009. Impairment in role functioning in mental and chronic medical disorders in the United States: results from the National Comorbidity Survey Replication. Mol. Psychiatry 14, 728-737. Crossref

- Elder, G. H., \& Giele, J. Z. (2009). The craft of life course research. New York, NY: Guilford Press

- Eliason, M. \& Storrie, D. (2009). Does job loss shorten life? Journal of Human Resources, 44(2), 277-302. Crossref

- Elliott, A. (2015). Identity troubles: An introduction. Abingdon, Oxon: Routledge. Crossref

- Endler, N. S., Speer, R. L., Johnson, J. M., \& Flett, G. L. (2001). General self-efficacy and control in relation to anxiety and cognitive performance. Current Psychology, 20, 36-52. doi: 10.1007/s12144-001-1002-7 Crossref

- Erikson, E. (1968). Identity: Youth and crisis (2. print. ed.). New York: Norton.

- Fabian, E. (2013). Work and disability. In D. L. Blustein (Ed.), The Oxford handbook of the psychology of working (pp. 185-201). New York, NY: Oxford University Press. Crossref

- Flores, L., Navarro, R., \& Ali, S. (2017). The state of SCCT research in relation to social class: Future directions. Journal of Career Assessment, 25, 6-23. Crossref

- Flum, H. (2015). Relationships and career development: An integrative approach. In P. J. Hartung, M. L. Savickas, \& B. W. Walsh (Eds.), APA handbook of career intervention, volume 1: Foundations (pp. 145-158), Washington, DC: American Psychological Association. doi:10.1037/14438-009 Crossref

- Foa, E.B., Stein, D.J., McFarlane, A.C., 2006. Symptomatology and psychopathology of mental health problems after disaster. J. Clin. Psychiatry 67 (Suppl 2), 15-25.

- Frasquilho, D., Matos, M. G., Salonna, F., Guerreiro, D., Storti, C. C., Gaspar, T., \& Caldasde-Almeida, J. M. (2015). Mental health outcomes in times of economic recession: a systematic literature review. BMC public health, 16(1), 115. Crossref

- Gangopadhyaya, A., \& Garrett, A. B. (2020). Unemployment, Health Insurance, and the COVID-19 Recession. Health Insurance, and the COVID-19 Recession (April 1, 2020). Crossref

- Gathergood, J., 2013. An instrumental variable approach to unemployment, psychological health and social norm effects. Health Economics, 22(6), pp.643-654 Crossref

- Giorgi, G., Arcangeli, G., Mucci, N., \& Cupelli, V. (2015). Economic stress in the workplace: the impact of fear of the crisis on mental health. Work, 51(1), 135-142. Crossref

- Green, F., 2011. Unpacking the misery multiplier: How employability modifies the impacts of unemployment and job insecurity on life satisfaction and mental health. Journal of Health Economics, 30(2), pp.265-276. Crossref

- Greenglass, E., Antonides, G., Christandl, F., Foster, G., Katter, J. K., Kaufman, B. E., \& Lea, S. E. (2014). The financial crisis and its effects: Perspectives from economics and psychology. Journal of Behavioral and Experimental Economics, 50, 10-12. Crossref

- Heath, N. M., Hall, B. J., Russ, E. U., Canetti, D., \& Hobfoll, S. E. (2012). Reciprocal relationships between resource loss and psychological distress following exposure to political violence: An empirical investigation of COR theory's loss spirals. Anxiety, Stress \& Coping, 25(6), 679-695. Crossref

- Hobfoll, S. E. (2011). Conservation of resources theory: Its implication for stress, health, and resilience. The Oxford handbook of stress, health, and coping, 127, 147. Crossref 
- Hobfoll, S. E., Freedy, J., Lane, C., \& Geller, P. (1990). Conservation of social resources: Social support resource theory. Journal of Social and Personal Relationships, 7(4), 465-478. Crossref

- Hogg, M. A. (2007). Uncertainty-identity theory. Advances in Experimental Social Psychology, 39, 69-126 (San Diego, CA, US: Elsevier Academic Press. x, 429 in Zanna, Mark P). Crossref

- Huang GH, Niu X, Lee C, Ashford SJ. 2012a. Differentiating cognitive and affective job insecurity: antecedents and outcomes. J. Organ. Behav. 33(6):752-69 Crossref

- Huang GH, Zhao HH, Niu XY, Ashford SJ, Lee C. 2013. Reducing job insecurity and increasing performance ratings: Does impression management matter? J. Appl. Psychol. 98(5):852-62 Crossref

- Huber, M., Lechner, M. and Wunsch, C. (2011). Does leaving welfare improve health? Evidence for Germany, Health Economics 20(4): 484-504 Crossref

- Hudaykulov, A., Hongyi, X. \& Galib, M.A. (2015). Impact of Goal Orientation Theory on Social Capital: The Implications for Effective Team Cooperation in Uzbekistan Textile Industry. International Journal of Management Science and Business Administration, 1(6), 58-71. Crossref

- Hussain, A., Weisaeth, L., \& Heir, T. (2011). Psychiatric disorders and functional impairment among disaster victims after exposure to a natural disaster: a population based study. Journal of Affective Disorders, 128(1-2), 135-141. Crossref

- Iyengar, S. The Art of Choosing; Twelve: New York, NY, USA, 2010. Crossref

- Jeanne Leininger, L., \& Kalil, A. (2014). Economic strain and children's behavior in the aftermath of the Great Recession. Journal of Marriage and Family, 76(5), 998-1010. Crossref

- Jesus, S. N., Leal, A. R., Viseu, J. N., Valle, P., Matavelli, R. D., Pereira, J., \& Greenglass, E. (2016). Coping as a moderator of the influence of economic stressors on psychological health. Análise Psicológica, 34(4), 365-376. Crossref

- Jofre-Bonet, M., Serra-Sastre, V. and Vandoros, S., 2018. The impact of the Great Recession on health-related risk factors, behaviour and outcomes in England. Social Science \& Medicine, 197, pp.213-225. Crossref

- Johansson, T. (2006). Makeovermani: Om Dr phil, plastikkirurgi och illusionen om det perfekta jaget [Makeovermania: On Dr phil, plastic surgery and the illusion of the perfect self]. Stockholm: Natur \& Kultur.

- Kawohl, W., \& Nordt, C. (2020). COVID-19, unemployment, and suicide. The Lancet Psychiatry, 7(5), 389-390. Crossref

- Kernberg, O. F. (1985). Borderline conditions and pathological narcissism. Oxford: Rowman and Littlefield

- Laing, R. D. (1960). The divided self London

- Lazarus, R. and S. Folkman (1984): Stress, appraisal, and coping, Springer Publishing Company

- Leon, G.R., 2004. Overview of the psychosocial impact of disasters. Prehosp. Disaster Med. 19, 4-9 Crossref

- Lim AY, Lee S-H, Jeon Y, Yoo R, Jung H-Y. Job-seeking stress, mental health problems, and the role of perceived social support in university graduates in Korea. J Korean Med Sci (2018) 33:149. Crossref

- Lipari, F. (2018). This Is How We Do It: How Social Norms and Social Identity Shape Decision Making under Uncertainty. Games, 9(4), 99. Crossref

- Lo, C., \& Cheng, T. (2014). Race, unemployment, and chronic mental illness: A 15 year trend analysis. Social Psychiatry Epidemiology, 49, 1119-1128. Crossref

- Lucero, J. L., Lim, S., \& Santiago, A. M. (2016). Changes in economic hardship and intimate partner violence: A family stress framework. Journal of family and economic issues, 37(3), 395-406. Crossref 
- Luyckx, K., Schwartz, S. J., Goossens, L., Beyers, W., \& Missotten, L. (2011). Processes of personal identity formation and evaluation. In S. J. Schwartz, K. Luyckx and V. L. Vignoles (Eds.), Handbook of identity theory and research (pp. 77-98). New York: Springer. Crossref

- Mannerström, R., Muotka, J., \& Salmela-Aro, K. (2019). Associations between identity processes and success in developmental tasks during the transition from emerging to young adulthood. Journal of Youth Studies, 22(9), 1289-1307. Crossref

- Marcus, J. (2012). The effect of unemployment on the mental health of spouses. Crossref

- Margaretha, M. \& Wicaksana, A. (2020). The Relationship between Person Organization Fit Toward Organizational Commitment and Organizational Citizenship Behavior: Experiences from Student Activity Organization Members. International Journal of Management Science and Business Administration, 6(3), 43-49 Crossref

- Meltzer H, Bebbington P, Brugha T, Jenkins R, McManus S, Stansfeld S. Job insecurity, socioeconomic circumstances and depression. Psychol Med (2010) 40:1401-7. Crossref

- Murray, H. A. (1938). Explorations in personality. New York, NY: Oxford University Press.

- Neria, Y., Nandi, A., Galea, S., 2007. Post-traumatic stress disorder following disasters: a systematic review. Psychol. Med. 38, 467-480 Crossref

- Newman, A., Nielsen, I., Smyth, R., \& Hirst, G. (2018). Mediating role of Psychological capital in the relationship between social support and wellbeing of refugees. International Migration, 56(2), 117-132. Crossref

- Obrenovic, B., Du Jianguo, A. K., \& Khan, M. A. S. (2020). Work-family conflict impact on psychological safety and psychological well-being: a job performance model. Frontiers in psychology, 11. Crossref

- Oxoby, R.J. Cognitive dissonance, status and growth of the underclass. Econ. J. 2004, 114, 727-749 Crossref

- Parker, S. K. (2014). Beyond motivation Job and work design for development, health, ambidexterity, and more. Annual Review of Psychology, 65, 661-691. doi:10.1146/annurevpsych-010213-115208 Crossref

- Phillips, J., \& Nugent, C. (2014). Suicide and the Great Recession of 2007-2009: The role of economic factors in the 50 U.S. states. Social Science and Medicine, 116, 22-31. Crossref

- Prawitz, A., Garman, E. T., Sorhaindo, B., O'Neill, B., Kim, J., \& Drentea, P. (2006). InCharge financial distress/financial well-being scale: Development, administration, and score interpretation. Journal of Financial Counseling and Planning, 17, 34-50. Crossref

- Rabin, M. Cognitive dissonance and social change. J. Econ. Behav. Organ. 1994, 23, 177194. Crossref

- Reichert, A. R., \& Tauchmann, H. (2011). The causal impact of fear of unemployment on psychological health. Ruhr Economic Paper, (266). Crossref

- Reneflot A, Evensen M. Unemployment and psychological distress among young adults in the Nordic countries: a review of the literature. Int J Soc Welf(2014) 23:3-15. doi: 10.1111/ijsw.12000 Crossref

- Rosenblatt, Z., \& Ruvio, A. (1996). A test of a multidimensional model of job insecurity: The case of Israeli teachers. Journal of organizational behavior, 17(S1), 587-605. Crossref

- Ryan, R. M., \& Deci, E. L. (2000). "Self-determination theory and the facilitation of intrinsic motivation, social development, and well-being". American Psychologist, 55(1), 68-78. doi:10.1037/0003-066X.55.1.68 Crossref

- Ryan, R. M., \& Deci, E. L. (2000). Intrinsic and extrinsic motivations: Classic definitions and new directions. Contemporary Educational Psychology, 25, 54-67. doi:10.1006/ceps.1999.1020 Crossref

- Smith, L. (2015). Reforming the minimum wage: Toward a psychological perspective. American Psychologist, 70, 557-565. doi:10.1037/a0039579 Crossref

- Spiers, N., Qassem, T., Bebbington, P., McManus, S., King, M., Jenkins, R., ... \& Brugha, T. S. (2016). Prevalence and treatment of common mental disorders in the English national population, 1993-2007. The British Journal of Psychiatry, 209(2), 150-156. Crossref 
- Staufenbiel T, Konig CJ. 2010. A model for the effects of job insecurity on performance, turnover intention, " and absenteeism. J. Occup. Organ. Psychol. 83(1):101-1 Crossref

- Stuckler, D., Basu, S., Suhrcke, M., Coutts, A. and McKee, M., 2009. The public health effect of economic crises and alternative policy responses in Europe: an empirical analysis. The Lancet, 374(9686), pp.315-323. Crossref

- Thompson, M., Nitzarim, R., Her, P., Sampe, M., \& Diestelmann, J. (2017). Financial stress and work hope beliefs among adolescents. Journal of Career Assessment, 25, 254-267 Crossref

- Vander Elst T, Van den Broeck A, De Cuyper N, De Witte H. 2014b. On the reciprocal relationship between job insecurity and employee well-being: mediation by perceived control? J. Occup. Organ. Psychol. 87(4):671-93 Crossref

- Vignoles, V. L., Schwartz, S. J., \& Luyckx, K. (2011). Introduction: Toward an integrative view of identity. In S. J. Schwartz, K. Luyckx \& V. L. Vignoles (Eds.), Handbook of identity theory and research (pp. 1-27). New York: Springer Crossref

- Wanberg, C. R. (2012). The individual experience of unemployment. Annual Review of Psychology, 63, 369-396. doi:10.1146/annurev-psych-120710-100500 Crossref

- Wang HJ, Lu CQ, Siu OL. 2015. Job insecurity and job performance: the moderating role of organizational justice and the mediating role of work engagement. J. Appl. Psychol. 100(4):1249-58 Crossref

- Wetherell, M., \& Mohanty, C. T. (2010). The sage handbook of identities. Los Angeles: Sage

- Wright, K. D., Lebell, M. A. A., \& Carleton, R. N. (2016). Intolerance of uncertainty, anxiety sensitivity, health anxiety, and anxiety disorder symptoms in youth. Journal of Anxiety Disorders, 41, 35-42. Crossref

- Wu, D., Yu, L., Yang, T., Cottrell, R., Peng, S., Guo, W., \& Jiang, S. (2020). The Impacts of Uncertainty Stress on Mental Disorders of Chinese College Students: Evidence From a Nationwide Study. Frontiers in psychology, 11, 243. Crossref

- Yang T., Jiang S., Yu L., Cottrell R. R., Si Q. (2017b). Life stress, uncertainty stress and selfreported illness: a representative nationwide study of Chinese students. J. Public Health 26 205-209. 10.1007/s10389-017-0837-9 Crossref

- Yousaf, S., Rasheed, M. I., Hameed, Z., \& Luqman, A. (2019). Occupational stress and Montenegro (2010).

- Zandersen, M., Henriksen, M. G., \& Parnas, J. (2019). A recurrent question: what is borderline?. Journal of personality disorders, 33(3), 341-369. Crossref 